\title{
Multiscale modelling and team science: the future of orthopaedic biomechanics Marco Viceconti
}

\author{
Address: Laboratorio di Tecnologia Medica, Istituto Ortopedico Rizzoli, Bologna, Italy
}

Email: Marco Viceconti - viceconti@tecno.ior.it

from Ist Congress of the International Foot \& Ankle Biomechanics (i-FAB) community

Bologna, Italy. 4-6 September 2008

Published: 26 September 2008

Journal of Foot and Ankle Research 2008, I(Suppl I):K6 doi:I 0.II86/I757-I I46-I-SI-K6

This abstract is available from: http://www.jfootankleres.com/content/I/SI/K6

(c) 2008 Viceconti; licensee BioMed Central Ltd.

\section{Introduction}

Some of the most exciting developments in recent biomechanics research regard topics that lay at boundaries: boundaries between dimensional scales (i.e. cell-tissue interaction), between sub-systems (i.e. cardiovascular and musculoskeletal), or between different domains of biomedical knowledge (i.e. biology and engineering). This is a trend that we are observing in the entire biomedical research field, and undergoes the name of biomedical Integrative Research [1].

In order to follow this trend, every researcher needs to add to her tool chest two new tools: multiscale modelling, and team science.

\section{Multiscale modelling}

This term indicates the ability to models capable of predicting the physical behaviour of a complex system, which is regulated by multiple phenomena observable at radically different dimensional and/or temporal scales.

Given the level of complexity that integrative research involves, mathematical/numerical modelling appears the only viable option. However, this requires modelling methods that are not only multi-physics, but also multiscale.

The trivial declination of multiscale modelling are problems where all scale are regulated by exactly the same physics: if you need to model a single bolt whose loading is defined by the deformation of the entire car body, you have a significant difference in dimensions, but both models describe the elastic behaviour of a solid continuum; nowadays these problems are trivially solved with methods such as sub-structuring [2].

The true challenge is when each sub-model is a truly independent model, representing different physical behaviours, and most of the times using different mathematical approaches for the modelling. No off-the-shelf tool can currently solve this problem, but intense research activity is being conducted [3].

\section{Team science}

While multiscale modelling can help in integrating across sub-systems and across dimensional scales, to integrate across different domains of knowledge we need something else: team science. "Team science" refers to multipartnered and multi-disciplinary research partnerships designed to bring together specialized researchers to work on specific facets of a larger project or study. In the context of integrative research the need for team science is being addressed in three directions: the development of consensus processes involving stakeholders from very different sub-domains of biomedical research, such as the one we developed in STEP [1]; to create Internet communities specifically oriented to team science and its support, such as Biomed Town [4]; and to develop specialised pre-post processing environments for the multiscale modelling that help in capturing and exchanging knowledge across domains. This latter activity it is still in its infancy, but 
some seminal work is being done in the context of the MAF framework [5].

\section{References}

I. STEP Consortium: Seeding the EuroPhysiome: A Roadmap to the Virtual Physiological Human. [http://www.europhysi ome.org/roadmap]. [Online] 5 July 2007

2. Feng F, et al:: The mechanical and thermal effects of focused ultrasound in a model biological material. J Acoust Soc Am 2005, I I 7(4 Pt I):2347-55.

3. Viceconti M, et al.: Multiscale modelling of the skeleton for the prediction of the risk of fracture. Clin Biomech in press. $2008 \mathrm{Feb}$ 25. PMID: 183047I0.

4. Biomed Town: on-line Community for Integrative Research [http://www.biomedtown.org]

5. Viceconti $M$, et al.: The multimod application framework: a rapid application development tool for computer aided medicine. Comput Methods Programs Biomed 2007, 85(2): |38-5I.

Publish with Biomed Central and every scientist can read your work free of charge

"BioMed Central will be the most significant development for disseminating the results of biomedical research in our lifetime. "

Sir Paul Nurse, Cancer Research UK

Your research papers will be:

- available free of charge to the entire biomedical community

- peer reviewed and published immediately upon acceptance

- cited in PubMed and archived on PubMed Central

- yours - you keep the copyright

Submit your manuscript here:

http://www.biomedcentral.com/info/publishing_adv.asp 